\title{
OBSTETRIC OUTCOIME IN PREGNANCY WITH HEART DISEASE
}

KEY WORDS: Pregnancy,

heart disease, primigravida, and outcome.

\section{Dr. Shanaz Teng}

\section{Dr Mohmad} Anees Kar*
Professor and Head, Department of Obstetrics and Gynecology, Lal Ded Hospital, Srinagar,J\&K.

Registrar, Department of Obstetrics and Gynecology, Lal Ded Hospital, Srinagar,J\&K.*Corresponding Author

Background: Pregnancy associated with any form of heart disease is a challenge for both obstetrician and cardiologist. The advancement in surgical techniques \& minimal invasive surgeries have improved the prognosis of congenital lesions and many women even with severe defects are now reaching the child-bearing age. The number of pregnant women with coronary disease is expected to grow due to advanced maternal age and increased cardiovascular risk factors in women. Materials and Methods: This study was carried out in the department of Obstetrics and Gynecology in Lal Ded Hospital, an associated hospital of GMC, Srinagar. All the patients admitted in antenatal ward and delivered at period of gestation 28th weeks and beyond during the study period of 2019-2020 were included in the study. Results: Primigravida accounted for the majority group of heart disease with pregnancy and majority ( $90 \%)$ of them delivered at term and $10 \%$ had preterm delivery. Cardiac complications like pulmonary hypertension and congestive cardiac failure were present in $13.3 \%$ of cases. Conclusions: Rheumatic heart disease still remains the most common cardiac problems found in pregnant women. The incidence of heart disease in pregnancy was found to be $0.2 \%$ and majority of them belonged to 30-39 years group, un-booked and from rural background.

\section{Introduction}

Pregnancy associated with any form of heart disease is a challenge for both obstetrician and cardiologist. Cardiac disease has significant impact on maternal health during pregnancy, labor and deliveries. Even though heart disease complicates only 0.1 to $4 \%$ pregnancies worldwide but it contributes to significant amount of maternal mortality and morbidity. ${ }^{2,1,3}$ Improvements in health care services in recent decades have permitted more frequent identification of pregnant women with congenital and acquired heart disease. ${ }^{4}$ The advancement in surgical techniques \& minimal invasive surgeries has improved the prognosis of congenital lesions and many women even with severe defects are now reaching the child bearing age. In developed countries, congenital heart disease accounts for majority of heart disease in pregnancy, which is mainly due to decline in the incidence of rheumatic heart disease ${ }^{6}$ but rheumatic heart disease still is the commonest heart disease in pregnancy in developing countries. Hemodynamic changes during normal pregnancy are well tolerated by women with normal cardiac reserve. Diseased heart shows signs of decompensation with resultant increase in morbidity and mortality. It is natural to expect that the fetus would also be compromised in these mothers. Fetal health depends upon an adequate and continuous supply of well-oxygenated maternal blood. In uncompensated heart disease, the oxygen supply becomes limited and that result in compromised fetal growth, there can be growth restriction, premature birth or even fetal death. Women with heart disease who desire or anticipate pregnancy should have pre-conceptional counselling. Most women with heart disease have successful pregnancies, but complacency in the diagnosis and management of pregnant patients can have dire consequences for both the mother and the fetus. ${ }^{9}$ Heart diseases are the most important non obstetrical causes of maternal deaths during pregnancy, accounting for almost $20 \%$ of maternal deaths. ${ }^{4,10} \mathrm{~A}$ pregnant woman with heart disease who wish to continue pregnancy should have proper cardiac evaluation and should be managed by joint team of obstetrician, cardiologist, anesthetist and neonatologist. She should have regular cardiac function evaluation and planned elective delivery.

\section{Aims and Objectives of the study}

1. To determine the incidence of heart disease during pregnancy.
2. To evaluate the maternal and perinatal outcomes of pregnancies complicated by heart disease.

Materials and Methods: This study was carried out in the department of Obstetrics and Gynecology in Lal Ded Hospital, an associated hospital of GMC, Srinagar. All the patients admitted in antenatal ward and delivered at period of gestation 28th weeks and beyond during the study period of 2019-2020 were included in the study.

\section{Results and Analysis}

Total No. Of Deliveries: 16,968

Total No. of pregnancies with heart diseases delivered: 30 $(0.18 \%)$

Table 1: Distribution of Heart Diseases in Pregnancy by residence.

\begin{tabular}{|c|c|c|}
\hline Residence & Number of Cases & Percentage \\
\hline Urban & 5 & 16.7 \\
\hline Rural & 25 & 83.3 \\
\hline Total & 30 & 100.0 \\
\hline
\end{tabular}

In this study, as shown in table 1 , heart disease in pregnancy was more common in rural community $(83.3 \%)$ than urban community $(16.7 \%)$.

Table 2: Distribution of heart diseases in pregnancy by maternal age.

\begin{tabular}{|c|c|c|}
\hline Age & Number of cases & Percentage \\
\hline $20-29$ & 13 & 43.3 \\
\hline $30-39$ & 16 & 53.3 \\
\hline$\geq 40$ & 1 & 3.3 \\
\hline Total & 30 & 100.0 \\
\hline Mean \pm SD & \multicolumn{2}{|c|}{$30.46 \pm 5.78$} \\
\hline
\end{tabular}

Out of 30 cases, the maximum number of cases were found to be in the age group $30-39$ years (53.3\%), followed by $20-29$ years $(43.3 \%)$. There was only 1 case above 40 years, which is shown in table 2 .

Table 3: Distribution of heart diseases in pregnancy by parity.

\begin{tabular}{|c|c|c|}
\hline Parity & $\begin{array}{c}\text { Number of } \\
\text { cases }\end{array}$ & Percentage \\
\hline
\end{tabular}




\begin{tabular}{|c|c|c|}
\hline 0 & 15 & 50 \\
\hline 1 & 10 & 33.3 \\
\hline 2 & 4 & 13.3 \\
\hline$\geq 3$ & 1 & 3.3 \\
\hline Total & 30 & 100.0 \\
\hline
\end{tabular}

In the study, heart disease in pregnancy were more common in primigravidas (50\%) compared to para 1 (33.3\%), para 2 $(13.3 \%)$ and para $\geq 3(3.3 \%)$, as shown in table 3 .

Table 4: Distribution of heart diseases in pregnancy by gestational age at the time of delivery

\begin{tabular}{|c|c|c|}
\hline $\begin{array}{c}\text { Gestational age } \\
\text { (in weeks) }\end{array}$ & $\begin{array}{c}\text { Number of } \\
\text { cases }\end{array}$ & Percentage \\
\hline$<36+6$ & 3 & 10 \\
\hline $37-40$ & 25 & 83.3 \\
\hline $40+1-42$ & 2 & 6.7 \\
\hline Total & 30 & 100.0 \\
\hline
\end{tabular}

Above table shows that 25 cases (83.3\%) delivered after completing 37 weeks, preterm deliveries was observed in 3 cases $(10 \%)$ of study group. Only 2 cases $(6.7 \%)$ delivered beyond 40 weeks, no post term deliveries observed in the study.

Table 5: Distribution of heart diseases in pregnancy by booked status

\begin{tabular}{|c|c|c|}
\hline Booked Status & $\begin{array}{c}\text { Number of } \\
\text { cases }\end{array}$ & Percentage \\
\hline Booked & 13 & 43.3 \\
\hline Un-booked & 17 & 56.7 \\
\hline Total & 30 & 100.0 \\
\hline
\end{tabular}

Out of 30 cases, 17 were unbooked $(56.7 \%)$ and 13 were booked (43.3\%) as shown in table.

Table 6: Distribution of types of heart diseases in pregnancy.

\begin{tabular}{|c|c|c|}
\hline Types & Number of Cases & Percentage \\
\hline RHD & 19 & 63.3 \\
\hline CHD & 8 & 26.7 \\
\hline Misc. & 3 & 10 \\
\hline Total & 30 & 100.0 \\
\hline
\end{tabular}

Most common heart disease in pregnancy in this study was found to be Rheumatic Heart Disease (RHD) (63.3\%), followed by Congenital Heart Disease (CHD) (26.7 \%). Only 3 cases of miscellaneous heart disease was found (10\%) as shown in the table above.

Table 7: Distribution of different lesions of RHD.

\begin{tabular}{|c|c|c|}
\hline Types of RHD & Number of Cases & Percentage \\
\hline MS & 5 & 26.3 \\
\hline MS+AR & 3 & 15.7 \\
\hline MS+TR & 2 & 10.5 \\
\hline MR+AR & 1 & 5.2 \\
\hline MS+AR+TR & 1 & 5.2 \\
\hline MR+TR & 4 & 21.4 \\
\hline TR & 1 & 5.2 \\
\hline AS & 2 & 10.5 \\
\hline Total & 19 & 100.0 \\
\hline
\end{tabular}

In this study, isolated MS (26.3\%) was found to be the most common lesion among RHD, followed by combination of MR+TR (21.4\%) as shown in Table above.

Table 8: Distribution of different lesions of CHD.

\begin{tabular}{|c|c|c|}
\hline Types of CHD & Number of cases & Percentage \\
\hline VSD & 1 & 12.5 \\
\hline ASD & 4 & 50 \\
\hline PDA & 2 & 25 \\
\hline
\end{tabular}

\begin{tabular}{|c|c|c|}
\hline TOF & 1 & 12.5 \\
\hline Total & 8 & 100.0 \\
\hline
\end{tabular}

Atrial Septal Defect (ASD) (50\%) was the commonest lesion among CHD, followed by Patent Ductus Arteriosus (PDA) (25 $\%$ ) in this study as shown in table above.

Table 9:Distribution of NYHA grading on admission

\begin{tabular}{|c|c|c|}
\hline NYHA & Number of cases & Percentage \\
\hline I & 10 & 33.3 \\
\hline II & 15 & 50 \\
\hline III & 5 & 16.7 \\
\hline IV & 0 & 0 \\
\hline Total & 30 & 100.0 \\
\hline
\end{tabular}

As shown in the table above, majority of the cases were found to have NYHA grade I-II (83.3\%). 16.7\% cases of NYHA grade III were found. No case of NYHA grade IV was found.

Table 10: Distribution of cardiac complications:

\begin{tabular}{|c|c|c|}
\hline $\begin{array}{c}\text { Cardiac } \\
\text { Complications }\end{array}$ & $\begin{array}{c}\text { Number of } \\
\text { cases }\end{array}$ & Percentage \\
\hline CCF & 1 & 3.3 \\
\hline PAH & 3 & 10 \\
\hline
\end{tabular}

Only 3 cases had pulmonary hypertension (10\%) and 1 case had congestive cardiac failure (3.3\%) in this study, as shown in table.

Table 11: Distribution of obstetric complications.

\begin{tabular}{|c|c|c|}
\hline $\begin{array}{c}\text { Obstetric } \\
\text { Complications }\end{array}$ & Number of cases & Percentage \\
\hline Anaemia & 2 & 6.6 \\
\hline PPH & 1 & 3.3 \\
\hline Preterm Labour & 3 & 10 \\
\hline
\end{tabular}

As shown in the table above, preterm labour (10\%) is the commonest obstetric complication followed by anaemia $(6.6$ $\%$ ) in the study. There was l case of PPH (3.3\%).

Table 12: Distribution of mode of delivery

\begin{tabular}{|c|c|c|}
\hline Mode of Delivery & Number of cases & Percentage \\
\hline NVD & 5 & 16.3 \\
\hline Ventouse VD & 7 & 23.3 \\
\hline Forceps VD & 1 & 3.3 \\
\hline Em LSCS & 12 & 40 \\
\hline El LSCS & 4 & 13.3 \\
\hline VBAC & 1 & 3.3 \\
\hline Total & 30 & 100 \\
\hline
\end{tabular}

In this study, majority of the patients delivered by Em LSCS (40 $\%$ ), followed by Ventouse VD (23.3\%). 4 cases had NVD (13.3 $\%)$ also 4 cases had El LSCS (13.3\%). There were 1 each Forceps VD, Preterm VD andVBAC respectively (3.3\%).

Table 13: Distribution of onset of labour

\begin{tabular}{|c|c|c|}
\hline Onset & Number of cases & Percentage \\
\hline Induced & 4 & 15.4 \\
\hline Spontaneous & 22 & 84.6 \\
\hline
\end{tabular}

In the table above, spontaneous onset of labour was seen in $86.7 \%$ and in $13.3 \%$ labour was induced.

Table 13: Distribution of birth weight

\begin{tabular}{|c|c|c|}
\hline $\begin{array}{l}\text { Birth Weight } \\
\text { (In kg) }\end{array}$ & Number of cases & Percentage \\
\hline$<2.5$ & 5 & 16.7 \\
\hline $2.5-3.4$ & 18 & 60 \\
\hline $3.5-4$ & 6 & 20 \\
\hline$>4$ & 1 & 3.3 \\
\hline Mean \pm SD & 2.93 & 0.55 \\
\hline
\end{tabular}


In this study, majority of the baby's birth weight was found to be 2.5-3.4 (60\%) followed by 3.5-4 (20\%). 16.7\% babies birth weight was below $2.5 \mathrm{~kg}$ and 1 baby's birth weight was more than $4 \mathrm{~kg}$.

Table 14: Distribution of Apgar score

\begin{tabular}{|c|c|c|}
\hline Apgar Score at 5min & $\begin{array}{c}\text { Number of } \\
\text { cases }\end{array}$ & Percentage \\
\hline$<9$ & 5 & $16.7 \%$ \\
\hline$>9$ & 25 & $83.3 \%$ \\
\hline
\end{tabular}

$83.3 \%$ of babies had apgar score of $>9$ at 5 minutes and $16.7 \%$ had $<9$ at 5 minutes.

\section{Table 15: Distribution of adverse neonatal outcome}

\begin{tabular}{|c|c|}
\hline Adverse neonatal outcome & Number of cases \\
\hline IUD & 0 \\
\hline Congenital anomaly & 0 \\
\hline Neonatal death & 0 \\
\hline NICU & 5 \\
\hline
\end{tabular}

\section{Discussion}

Heart disease continues to be a risk factor for maternal and neonatal morbidity and mortality in pregnant women where pregnancy in itself is a state of hemodynamic stress. This study reflects the maternal and fetal outcome in pregnant women with cardiac disease managed at a government hospital, which is also a tertiary care referral centre. Prevalence of heart disease in pregnancy varies from 0.1 to $4 \%$ in different studies $^{2,1,3}$. In our study, the incidence was $0.2 \%$, which is comparable with the studies conducted by Ashwini Met al ${ }^{10}$ $(0.4 \%)$ and Indira Iet $\mathrm{al}^{6}(0.43 \%)$. Most of our patients had RHD $(63.3 \%)$ which was also found to be the major form of heart disease in studies done by Ashwini $\mathrm{M}$ et $\mathrm{al}^{10}(66.7 \%)$ and Kapoor P et al ${ }^{4}(64.9 \%)$. Mitral stenosis (26.3\%) was the commonest lesion among acquired disease which was similar to Indira I et al ${ }^{6}(25 \%)$ however this is not in agreement with the findings of Sawhney $\mathrm{H}$ et al ${ }^{16}(89.2 \%)$.Congenital heart disease accounted for $26.7 \%$ of cases, results were comparable with studies done by Nayak R et $\mathrm{al}^{8}(26.6 \%)$ and Sawhney $\mathrm{H} \mathrm{et} \mathrm{al}^{16}(26.1 \%)$ but in difference with the findings of Siu S et al ${ }^{14}(74 \%)$ which is due to decline in incidence of rheumatic origin of heart diseases in western countries. Atrial septal defect was diagnosed in $50 \%$ patients which is similar with the findings of Koregol $\mathrm{M}$ et $\mathrm{al}^{13}$. None of these patients had any history of surgery done for correcting the cardiac anomaly. In our study, Primigravida (50\%) accounted for the major group, similar results were noted in study by Koregol M et $\mathrm{al}^{13}(52.7 \%)$.

In our study, majority ( $90 \%$ ) of the patients delivered at term and $10 \%$ had preterm delivery which is comparable with the study done by Kapoor P et al ${ }^{4}$. Out of total 30 patients, $16(53.3 \%)$ had caesarean delivery and remaining 14 $(46.6 \%)$ had vaginal delivery. These observations were similar to study done by Thakkar J et al ${ }^{5}$ which showed that, $60 \%$ of cases had caesarean delivery and $40 \%$ delivered vaginally. Our institution being the referral center, majority of cases were referred from peripheral settings for various obstetric indications for which caesarean delivery was required. Among the vaginal deliveries,5(16.3\%) patients had a normal vaginal delivery while 8 patients (26.6\%) underwent instrumental delivery (vacuum delivery in our study, 1 had outlet forceps delivery) to cut down the second stage of labor. 1 patient hadVBAC.These are comparable with the findings of study done by Kapoor $\mathrm{P}$ et al ${ }^{4}$ which shows 20.2 $\%$ of instrumental deliveries. Most (53.3\%) patients in this study were in the age group of 30-39 years, mean maternal age was $30.46 \pm 5.78$. 1 patient was $>40$ years. In a study by Nayak R et al ${ }^{8}$ majority (70\%) of the patients were in age group of 20-29 years. Advanced age in this study may be due to high literacy rate and career pursuit. Majority were from rural background an unbooked. Cardiac complications were present in $4(13.3 \%)$ cases. These included 3 cases of pulmonary hypertension and $1(3.3 \%)$ case of congestive cardiac failure. There was no maternal mortality and no ICU admission was required. In our series mean birth weight was $2.93 \pm 0.55 \mathrm{~kg}$, smallest being $1.7 \mathrm{~kg}$ and largest being $4.4 \mathrm{~kg}$. Out of 30 babies 27 babies delivered at term and 3 babies delivered preterm. 5 (16.7\%) babies were low birth weight which is in difference to findings of other studies ${ }^{4}$, which is possible because of average weight of babies are more in this institute.5 (16.7\%) babies had Apgar score less than $9 / 10$ at 5 minutes which is comparable with the findings of Koregol $\mathrm{M}$ et $\mathrm{al}^{13}$

\section{Conclusion}

Incidence of heart disease in pregnancy in the study was found to be $0.2 \%$. Mean age of the patients were $30.46 \pm 5.78$ years and majority of them belonged to $30-39$ years group and were unbooked, from rural background. Cardiac complications were seen in $13.3 \%$ of cases and preterm labor $(10 \%)$ was the commonest obstetric complications. Most of the patients (83.34\%) delivered at 37-42 weeks and 53.3\% had caesarean delivery. Mean birth weight was $2.93 \pm 0.55 \mathrm{~kg}$ and $83.3 \%$ babies had Apgar Score of $>9$ at 5 minutes.

\section{References}

[1] Chinchawade V, Daver R, Lewis P. Maternal outcome in heart disease in pregnancy. RRJ Med Health Sci 2014;3(3):61-66.

[2] Nqayana T, Moodley J, Naidoo D. Cardiac disease in pregnancy. Cardio vasc J Afr 2008; 19(3):145-151.

[3] Yasmeen N, Aleem M, Iqbal N. Feto-Maternal Outcome in Patients with Cardiac Disease in Pregnancy. PakJ Med Health Sci 201 1;5(4):748-51.

[4] Kapoor P, Agarwal R, Kohli U, Jose T, Singh S. Evaluation of fetomaternal outcome in pregnancies complicated by heart disease: our experience at a tertiary care centre. Int J Reprod Contracept Obstet Gynecol 2016;5(7):226973.

[5] Thakkar J, Yadav P,Vyas R. A Study of Pregnant Women with Cardiac Disease. IOSR J Dental Med Sci 2016;15(3):27-29.

[6] Indira I, Sunitha K and Jyothi. Study of Pregnancy Outcome in Maternal Heart Disease.IOSR J Dental Med Sci 2015; 14(7):06-10

[7] Cunningham FG, Leveno KJ, Bloom SL, Spong CY, Dashe JS, Hoffman BL, Casey BM, Sheffield JS, editors. Williams obstetrics. 24th ed. New York: mcgraw-Hill; 2014.

[8] Nayak R, Patil S, Laddad M. Pregnancy with heart disease-fetomaternal outcome. Int J Recent Trends Sci Techno 2014;11(2):169-172.

[9] Akhtar N, Sultana T, Sayeeda S, Parveen T, Begum F. A Study on Pattern of Heart Disease and Maternal and Fetal Outcome of Pregnancy in a Tertiary Level Hospital.Uni Heart J2015; 11(1):36-41.

[10] Ashwini M, Devi G. Maternal and fetal outcome in cardiac disease complicating pregnancy at a tertiary centre in a rural area. Int J Biomed Res 2014;5(3):200-03.

[11] Sen M, Bhattacharyya P, Chowdhury N. Pregnancy with heart diseaseFetomaternal outcome.J Evo Med Dental Sci 2014;3(5):1178-82

[12] Puri S, Bharati A, Mohan B, Bindal V, Verma S. Maternal heart disease and pregnancy outcomes.JK SciJ Med Edu Res 2013;15(1):7-10.

[13] Koregol M, Mahale N, Nayak R, Bhandary A. Maternal and perinatal outcomes of pregnancies complicated by cardiac disease. J Turkish-German gynecolassoc 2009; 10:30-4.

[14] Siu S, Sermer M, Colman J, Alvarez A, Mercier L, Morton B, et al. Prospective multicentre study of pregnancy outcome in women with heart disease. Circulation 2001; 104(5):515-21.

[15] Sawhney H, Suri V, Vasishta K, Gupta N, Devi K, Grover A. Pregnancy and congenital heart disease: maternal and foetal outcome. Aust NZ J Obstet Gynaecol 1998;38(3):266-71.

[16] Sawhney H, Aggarwal N, Suri V,Vasishta K, Sharma Y, Grover A. Maternal and perinatal outcome in rheumatic heart disease. Int. J Gynaecol Obstet 2003; 80:9-14. 